\title{
Study on the Conflicts between Work and Family at the Kashan University of Medical Sciences, Iran
}

\author{
Ali Kebriaei ${ }^{1, a^{*}}$, Fatemeh Abedizadeh ${ }^{1, b}$, Teyebehsadat Sharifian ${ }^{1, c}$ \\ ${ }^{1}$ Department of Public Health, School of Health, Kashan University of Medical Sciences, \\ Kashan, Iran \\ akebria_noosh@yahoo.com, ํㅏarbaf423@gmail.com, mehkaz73@yahoo.com.
}

Keywords: work-family conflict, employees, Iran.

\begin{abstract}
With both professional and personal responsibilities, employees often conflict when reconciling the demands of family and work. The study aimed to investigate whether work to family conflict experienced by employees of Kashan University of medical sciences differed from family to work conflict. A cross sectional study was carried out in 2014. A random sample of 202 employees in the four schools affiliated with Kashan University of medical sciences located in central of Iran was selected and responded to items of the questionnaires using a 7-point Likert scale. Work-family conflict was measured using Carlson et al.'s 18 items scale. Higher values indicate higher levels of work to family conflict and family to work conflict. Analysis was carried out using SPSS 16. Employees experienced work-family conflict in the two directions. Work to family conflict with mean of $31.55 \pm 10.68$ was significantly $(\mathrm{t}=9.87, \mathrm{P}<0.001)$ more than family to work conflict with $25.58 \pm 8.77$. They experienced different time-, strain-, and behavior-based work to family conflicts than time-, strain-, and behavior-based family to work conflicts $(\mathrm{P}<0.01)$. Work to family conflict was more than family to work conflict. Therefore, University authorities should try to improve working conditions through changing the working culture and re-looking into their work structure and employment policies to moderate the experience of work to family conflicts encountered by the employees.
\end{abstract}

\section{Introduction}

Family and work are the two most important aspects of adults' lives [1]. With both professional and personal responsibilities, people are faced with a significant challenge and they often conflict when reconciling the demands of family and work. The pressures of multiple roles and trying to manage their demands lead to reduced resources and increased strain in the form of work-family conflict [2]. Work-family conflict defined as a form of friction in which role pressures from the work and family domains are mutually incompatible in some respects. That is, participating in the work (family) role is made more difficult by virtue of participation in the family (work) role [3]. Conceptually, conflict between work and family is a bi-directional nature. Most researchers make the distinction between what is termed work to family conflict, and what is termed family to work conflict. Work to family conflict occurs when experiences at work interfere with family life. Family to work conflict occurs when experiences in the family interfere with work life [4].

Greenhaus et al [3] suggest that work-family conflict exists when (a) time devoted to the requirements of one role makes it difficult to fulfill requirements of another; (b) strain from participation in one role makes it difficult to fulfill requirements of another; and (c) specific behaviors required by one role make it difficult to fulfill the requirements of another[3]. Therefore three distinct forms of work-family conflict were introduced, namely time-based conflict, strainbased conflict, and behavior-based conflict [5]. In addition, the multi-dimensional nature of workfamily conflict occurs in each direction [6].

Conflict between work and family is important for organizations and people because it is a growing source of stress for most employees internationally and is linked to negative consequences $[7,8]$. A variety of studies show that work-family conflict brings costly and negative consequences 
for individuals and organization, including emotional exhaustion [9], depressive behavior [10, 4], decreased physical and mental health [11, 12], lower job satisfaction [13], organizational commitment [14] and job performance $[15,16]$.

The rationale for focusing on the work-family conflict among higher education employees lies in the fact that universities' employees specially faculty members play an important role in achieving the higher education goals and universities, which understand employees' viewpoints can capture an accurate picture of where needs lie. Consequently they can actively engage in activities aimed at reducing work-family conflict.

Although the work-family conflict has been tested in other occupational populations in Iran, few have been directed at the higher education and no research is known to differentiate the three forms of work-family conflict within the two directions [17-19].

Hence, the objectives of this study are to determine whether time, strain, and behavior based work to family conflicts experienced by employees of Kashan University of medical sciences differed from time, strain, and behavior based family to work conflicts.

\section{Materials and Methods}

This cross sectional study was carried out in 2014. The population of the study was 298 employees in the four schools affiliated with Kashan University of medical sciences located in central of Iran. The sample was made up of 202 of employees who were selected by simple random sampling method. A questionnaire survey was conducted to investigate the existence of the workfamily conflicts affecting employees in the schools. The questionnaire was divided into Parts A and B. Section A comprised questions about the background of the employees.

In the section B of the questionnaire, work-family conflict was measured using Carlson et al.'s [20] 18 item scale. The scale consists of six subscales (3 items each), measuring time-, strain-, and behavior-based conflict for both work to family conflict (WFC) and family to work conflict (FWC). The WFC scale measures the extent to which work interferes with family, while the FWC scale measures the extent to which family interferes with work.

Participants responded to items of the questionnaire using a 7-point Likert scale ranging from 1 (strongly disagree) to 7 (strongly agree). The total possible score ranges from 3 to 21 for each of the three forms of conflicts in the both WFC and FWC directions. For each forms, the scores were then summed and divided by the number of items to attain an item mean. Higher values indicate higher levels of WFC and FWC.

Results of earlier studies demonstrated good reliability and validity of the Iranian version of the work-family scale $[18,19]$. In the present study, the Cronbach's alpha coefficients of WFC and FWC were 0.87 and 0.81 respectively.

According to Hair et al. Cronbach's alpha coefficients equal to or more than .7 has adequate reliability [21].

Analysis was carried out using SPSS for Windows (version16.0). Descriptive statistics (mean and standard deviation) were used to study the distribution of data. T-test and one-way ANOVA were used to compare conflict among demographic groups $(\alpha=0.05)$. Paired t-tests were then used to compare mean scores and to determine whether each of the three forms of conflict (time, strain and behavior), which respondents experience, is different between the WFC direction and the FWC direction.

\section{Findings}

After the distribution of the questionnaires to the employees, 185 (91.5\%) completed questionnaires were returned. The results show the mean age of the respondents was $41.26 \pm$ 8.13 years, ranging from 24 to 60 . Fifty and three percent of the respondents were male. The majority $(86.5 \%)$ of the respondents were married. Mean number of working years was $15.71 \pm$ 7.91 , ranging from 1 to 29 . Table 1 shows the other demographic variables of the respondents. 
Table 1. Summary of Respondents’ Demographics ( $\mathrm{N}=185)$.

\begin{tabular}{|lll|}
\hline Variables & No. $\%$ \\
\hline Education Degree & & \\
High school graduate & 28 & 15.1 \\
Associate & 12 & 6.5 \\
bachelor & 52 & 28.1 \\
Master & 46 & 24.9 \\
Doctoral & 47 & 25.4 \\
\hline Marital Status & & \\
Married & 160 & 86.5 \\
Single & 25 & 13.5 \\
\hline Working place & & \\
Health & 31 & 16.8 \\
Medicine & 88 & 47.6 \\
Nursing & 34 & 18.3 \\
Para-Medical & 32 & 17.3 \\
\hline executive position & & \\
Yes & 41 & 22.2 \\
No & 144 & 77.8 \\
\hline
\end{tabular}

Figure 1. indicates a general agreement that employees' experiences of conflict in the two directions (WFC \& FWC) was prevalent and pervasive. More than half of the employees experienced medium and high levels of work to family conflict and More than $45 \%$ of them encountered medium and high levels of family to work conflict (Fig. 1).

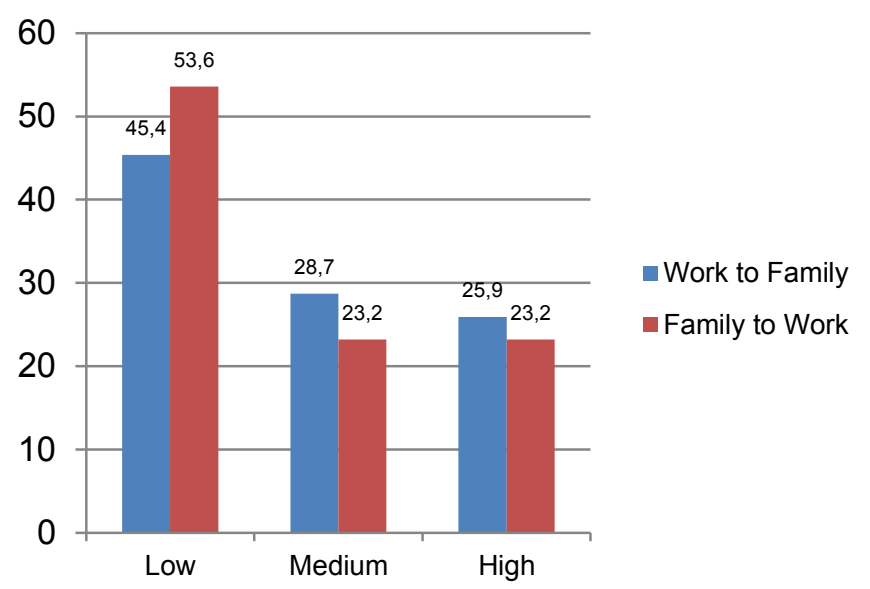

Fig. 1. Frequency of work to family conflict and family to work conflict among respondents.

The results support the differentiation between work to family conflict and family to work conflict. Work to family conflict with mean of $31.55 \pm 10.68$ was significantly $(\mathrm{t}=9.87, \mathrm{P}<0.001)$ more than family to work conflict with $25.58 \pm 8.77$.

Mean of work to family conflict and mean of family to work conflict differ in the three types of conflicts and these differences are significant (Table 2). This suggests strain-based work to family conflict to be the highest, followed by time-based conflict and behavior-based conflict. Also, behavior-based family to work conflict to be the lowest, followed by time-based conflict and strainbased conflict (Table 2). 
Table 2. Means, standard deviations, and t-values for three types of work to family and family to work conflict.

\begin{tabular}{|l|l|l|c|c|}
\hline \multirow{2}{*}{ Conflict Type } & \multicolumn{2}{|c|}{ Direction of Conflict } & & \\
\cline { 2 - 5 } & $\begin{array}{l}\text { Work to Family } \\
\text { (Mean } \pm \text { standard deviation })\end{array}$ & $\begin{array}{l}\text { Family to Work } \\
\text { (Mean } \pm \text { standard deviation) }\end{array}$ & t & PV \\
\hline Time Based & $10.29 \pm 4.93$ & $8.73 \pm 4.16$ & 4.39 & $<0.001$ \\
\hline Strain Based & $11.19 \pm 4.71$ & $7.38 \pm 3.89$ & 11.04 & $<0.001$ \\
\hline Behavior Based & $10.07 \pm 3.74$ & $9.47 \pm 3.69$ & 2.59 & 0.01 \\
\hline
\end{tabular}

Therefore, the hypothesis that employees of Kashan University of medical sciences experience different time-, strain-, and behavior-based work to family conflicts than time-, strain-, and behavior-based family to work conflicts was accepted (Table 2).

There are no relationship between the demographic variables and work to family and family to work conflicts.

\section{Discussion}

As noted at the outset, this study is a cross sectional one, examining the difference between work to family conflict and family to work conflict. The hypothesis of the study was supported and employees of Kashan University of medical sciences experienced greater work to family conflict than family to work conflict. A plausible explanation is that job responsibilities that must be managed on daily basis requires large investments of time, concentration and emotion, that there is little time and energy remaining for other domains such as family life. This finding is similar to result of work of Nasurdin and O'Driscoll [22], Ogbogu and Erero [23], and Kovner et al. [24] and is inconsistent with Yildirim and Aycan [25].

In line with some other studies [23] and inconsistent with others ones [18, 26], in our study respondents experienced the highest conflict in the strain-based type of the work to family direction.

A significant correlation between work to family conflict and family to work conflict $(\mathrm{r}=0.66$, $\mathrm{P}<0.001$ ) suggest that as levels of work to family conflict increase, the experience of family to work conflict increases too. This finding is consistent with the work of Oujian et al. [18] and in contrary with some other studies Burke and Greenglass [27].

The results indicate problems do exist between work and family life. For employees it is important that their organization be concerned about work-family conflicts and that they are given sufficient resources to both do their work and handle their non-work requirements [28]. It is therefore pertinent that closer attention be paid to the work-family conflict of employees.

In this regard, a number of practical suggestions can be traced. First, it is crucial to note that management should not view the work-family conflict only as an individual problem and responsibility [29] and should place the work-family issue as an enterprise priority.

Second, it is recommended that management should adopt family oriented benefits like flexible working arrangements, paid recreation, holidays, remuneration, work off opportunities to spend appropriate time with family, child care centers at workplace, workplace and manager support, training to cope up in tough working schedules etc. in general, management should try to become a supportive and family-friendly organization so that employees could achieve the balance between family and work life.

The study has employed a single university which limits the generalization of the findings. The current study only investigates work-family conflict so future studies can be conducted to survey relationship between work-family conflict and other variables like productivity and turnover etc. 


\section{Conclusions}

The study revealed that employees working in the Kashan University of medical sciences experienced the different time-, strain-, and behavior-based conflict in the WFC direction higher than FWC direction. Therefore, it is recommended that University authorities should try to improve working conditions through changing the working culture and re-looking into their work structure and employment policies to moderate the experience of work to family conflicts encountered by the employees.

\section{Acknowledgement}

We are appreciative to the employees who participated in the study and Mrs. Maryam Kebriaei for reviewing the manuscripts. We value schools authorities' for their managerial support.

\section{References}

[1] W.J. Casper et al., Work-family conflict, perceived supervisor support and organizational commitment among Brazilian professionals, Journal of Vocational Behavior. 79 (2011) 640.6-52.

[2] A.A. Grandey, R. Cropanzano, The conservation of resources model applied to work-family conflict and strain, Journal of vocational behavior. 54 (1999) 350-370.

[3] J.H. Greenhaus, N.J. Beutell, Sources of conflict between work and family roles, Academy of management review. 10 (1985) 76-88.

[4] G.M. Bellavia, M.R. Frone, Work-family conflict, In: J. Barling, E.K. Kelloway, M.R. Frone (Eds.), Handbook of work stress, Thousand Oaks, SAGE Publications, C, 2005, pp. 113-147.

[5] P. Brough, M. O’Driscoll, Work-family conflict and stress. In: A.S.G. Antoniou, C.L. Cooper (Eds.), Research Companion to Organizational Health Psychology, Cheltenham, Edward Elgar, UK, 2005, pp. 346-365.

[6] U. Yavas, E. Babakus, O.M. Karatepe, Attitudinal and behavioral consequences of workfamily conflict and family-work conflict: does gender matter?, International Journal of Service Industry Management. 19 (2008) 7-31.

[7] S.A. Poelmans, editor. Work and family: An international research perspective, Psychology Press, 2005.

[8] M.R.U. Khan et al., Work-Family Conflict and Turnover Intentions: Mediating Effect of Stress, International Journal of Humanities and Social Science. 4(5) (2014) 92-100.

[9] J.R. Halbesleben, A.R. Wheeler, A.M. Rossi, The costs and benefits of working with one's spouse: A two-sample examination of spousal support, work-family conflict, and emotional exhaustion in work-linked relationships, Journal of Organizational Behavior. 33 (2012) 597 615.

[10] J. Hao et al., Association between work-family conflict and depressive symptoms among Chinese female nurses: The mediating and moderating role of psychological capital, International journal of environmental research and public health. 12 (2015) 6682-6699.

[11] D.S. Carlson et al., Health and turnover of working mothers after childbirth via the workfamily interface: An analysis across time, Journal of Applied Psychology. 96 (2011) 1045.

[12] S. Mauno, U. Kinnunen, M. Rantanen, Work-family conflict and enrichment and perceived health: Does type of family matter?, Family Science. 2 (2011) 1-2.

[13] C.S. Bruck, T.D. Allen, P.E. Spector, The relation between work-family conflict and job satisfaction: A finer-grained analysis, Journal of vocational behavior. 60 (2002) 336-353. 
[14] S. Benligiray, H. Sönmez, Analysis of organizational commitment and work-family conflict in view of doctors and nurses, The International Journal of Human Resource Management. 23(18) (2012) 3890-3905.

[15] F.T. Amstad et al., A meta-analysis of work-family conflict and various outcomes with a special emphasis on cross-domain versus matching-domain relations, Journal of occupational health psychology. 16 (2011) 151-169.

[16] L.T. Eby et al., Work and family research in IO/OB: Content analysis and review of the literature (1980-2002), Journal of vocational behavior. 66 (2005) 124-197.

[17] M. Saatchi, N. Rezaei, Study communication between time management and work-family conflict, family-work conflict on productivity with Khuzestan cement factories, Journal of psychological researches. 2 (2011) 1-19.

[18] P. Oujian, F. Alhani, A. Tol, Reviewing the Work and Family Conflict and its Association with Quality of Life among Clinical Nurses, J. Health Syst. Res. 9 (2013) 345-353.

[19] M. Golparvar et al., The model of the effects of work-family conflict, job dangers and role overload on nurses' performance, Woman and study of family. 4 (2012) 83-98.

[20] D.S. Carlson, K.M. Kacmar, L.J. Williams, Construction and initial validation of a multidimensional measure of work-family conflict, Journal of Vocational behavior. 56 (2000) 249-276.

[21] J. Hair et al., Multivariate Data Analysis. 6th edition ed. Upper Saddle River, Prentice-Hall, USA, 2006.

[22] A.M. Nasurdin, M.P. O’Driscoll, Work overload, parental demand, perceived organizational support, family support, and work-family conflict among New Zealand and Malaysian academics, New Zealand Journal of Psychology. 41 (2012) 38-48.

[23] C.O. Ogbogu, E.J. Erero, An Assessment of the Institutional Factors Affecting Female Labour Input in the Nigerian University System, Asian Women. 25 (2009) 55-74.

[24] C. Kovner et al., Factors associated with work satisfaction of registered nurses, Journal of Nursing Scholarship. 38 (2006) 71-79.

[25] D. Yildirim, Z. Aycan, Nurses' work demands and work-family conflict: A questionnaire survey, International journal of nursing studies. 45 (2008) 1366-1378.

[26] S. Ahmad, M. Skitmore, Work-family conflict: A survey of Singaporean workers, Singapore Management Review. 25 (2003) 35-52.

[27] R.J. Burke, E.R. Greenglass, Work-family conflict, spouse support, and nursing staff wellbeing during organizational restructuring, Journal of occupational health psychology. 4 (1999) 327-336.

[28] E.E. Kossek et al., Workplace social support and work-family conflict: A meta-analysis clarifying the influence of general and work-family-specific supervisor and organizational support, Personnel psychology. 64 (2011) 289-313.

[29] K.K. Mihelic, M. Tekavcic, Work-family conflict: a review of antecedents and outcomes, International Journal of Management and Information Systems. 18 (2014) 15-25. 